\title{
Analysis of Difficulties of Junior High School Students in Solving Closed and Open Mathematical Problems
}

\author{
Rina Anggraeni ${ }^{1 *}$, Dadang Juandi ${ }^{2}$, Dian Usdiyana ${ }^{2}$ \\ ${ }^{I}$ Undergraduate Student of Mathematics Education Study Program, Faculty of Mathematics and Science Education, Universitas \\ Pendidikan Indonesia, Bandung, Indonesia \\ ${ }^{2}$ Department of Mathematics Education, Faculty of Mathematics and Science Education, Universitas Pendidikan Indonesia, \\ Bandung, Indonesia
}

*Corresponding author email: rinaanggraeni034@gmail.com

\begin{abstract}
This study aims to describe the difficulties of junior high school students in solving closed and open mathematical problems and to describe the causes of junior high school students experiencing these difficulties. As many as 25 students of class VIII-D from one of the State Junior High Schools in Bandung Regency were used as research samples. Data was collected by using test techniques, interviews, and document studies. The stages of data analysis carried out are data collection, data reduction, data presentation, and drawing conclusions. The results of the study showed that students had difficulty in converting the problem into a mathematical model, determining the required decision variables, calculating multiplication and division operations, and determining more than one answer in solving open problems. The difficulties experienced by these students are caused by the following: students feel that the problem given is something new, students are less careful in understanding the problems given, students still do not master the material, students are less careful in performing arithmetic operations, and students not accustomed to solving problems in the form of problem solving and open questions.
\end{abstract}

Keywords: Solving problems, closed problems, open problems

\section{Introduction}

Mathematics is a subject that is given to all levels of education, from basic education to higher education. This happens because mathematics has an important role in everyday life and can develop human thought patterns such as the ability to think critically, logically, systematically, creatively, tenacious and thorough in problem solving (Cockcroft, 1982). Therefore, mathematics learning must be managed properly in order to bring out these skills in students. The purpose of learning mathematics in the 2013 Curriculum attached to Appendix 3 of the Regulation of the Minister of Education and Culture number 58 (Kemendikbud, 2014: 325) is to use reasoning on properties, perform mathematical manipulations both in simplification, and analyze components in problem solving in and outside the context of mathematics which includes the ability to understand problems, build mathematical models, complete models, and interpret solutions obtained, including in solving problems in everyday life. From the objectives of learning mathematics that have been described, there are several competencies that are expected to be possessed by students after studying mathematics, one of which is that students can solve problems. The problem solving in question is that students can solve math problems that are different from the problems that have been given previously and have more complex characteristics appropriately.

Based on the structure, mathematical problems are divided into closed problems and open problems (Buchanan, 1987). Closed problems are problems that are clearly presented and have only one solution, while open problems are problems that have not been clearly specified and have more than one strategy or solution. Therefore, students must be accustomed to solving closed and open mathematical problems properly so that students are accustomed to facing and solving various difficult conditions in everyday life.

In the learning practices that have occurred so far, mathematics learning is accustomed to using closed mathematical problems (only having one solution) without providing open ended problems. This is in line with Stacey's opinion (2011) which reveals that the learning that has been carried out so far has put more emphasis on memorizing and finding the correct answer to the questions given. The habit of using closed math problems in 
learning can cause students to have difficulty when faced with open math problems. This can be seen based on research conducted by Mourtos et al. (2004), which states that students' ability in open-ended problem solving is still low.

Although students are accustomed to using closed problems in learning mathematics, in fact students' problem solving abilities in solving closed problems are not much different from students' problem solving abilities in solving open problems. This is in line with research conducted by Rusyda, Kusnandi, and Suhendra (2017) which states that the level of achievement of students' mathematical problem solving abilities in geometry is still low. This is because students are not accustomed to solving problems that measure mathematical problem solving abilities, weakness in remembering previous knowledge, and lack of problem solving frameworks. In addition, Retnawati and Heri (2017) states that the mathematical problem solving abilities of seventh grade junior high school students in Bandung City are in the moderate group where students experience obstacles when solving mathematical problems. Based on this, students' problem solving ability in solving open and closed problems is still low. The low ability of these students indicates that students cannot solve problems according to the predetermined problem-solving stage. This means that students have difficulty in solving closed and open mathematical problems.

In the 2013 curriculum which is applied in the learning process in junior high school, there is a subject about circles. Abidin and Retnawati (2019) say that in learning mathematics, the average score of students on the circle subject is low because students often make mistakes when solving problems given, especially in the discussion of the circumference and area of a circle. In addition, Wicaksono and Martyanti (2019) state that in solving mathematical problem solving problems on circle material, students make mistakes in the completion process. The completion process is not systematic, there are even students who give the final answer directly. Other errors are as follows: (a) errors in writing units of length, area, and volume, (b) errors in understanding the problem, (c) errors in making conclusions that are not relevant to the results of the solution, (d) errors in identifying images, and (e) errors in incomplete problem solving. These errors indicate that students have difficulty in solving mathematical problems on circle material.

Based on the description, the writer intends to analyze the students' difficulties in solving closed and open mathematical problems on the circle material. The purpose of this study was to describe the difficulties experienced by junior high school students in solving closed and open mathematical problems and to find out the factors that caused junior high school students to have difficulty solving closed and open mathematical problems. This research is expected to help readers to find out the difficulties experienced by junior high school students in solving closed and open problems so that these difficulties can be overcome immediately.

\section{Materials and Methods}

\subsection{Materials}

This study used qualitative research methods. The subjects in this study were 25 students of class VIII-D in one of the state junior high schools in Bandung Regency. The instruments used in this study were as follows: (a) 4 descriptive questions in the form of problem solving questions with 2 closed problems and 2 open problems related to the circle material, and (b) interview guidelines and document study. The open problem used is a problem that has more than one answer. The test questions compiled referred to the problem-solving indicators expressed by Retmawati and Heri (2017), namely as follows: (a) identify known and asked elements, (b) formulate problems or create mathematical models, (c) apply strategies to solve the problem, and (d) explain the results according to the original problem.

\subsection{Methods}

The data analysis stage used in this study is based on the model of Miles and Huberman (1994: 10-11) which consists of data reduction, data presentation, as well as drawing conclusions and verification. After the test was carried out, the results of student answers were scored by referring to the scoring rubric developed by Hamzah (2014) as presented in Table 1.

Table 1: Diagnostic Test Scoring Guidelines for Students' Difficulty in Solving Problems

\begin{tabular}{|l|l|l|}
\hline \multicolumn{1}{|c|}{ The aspects assessed } & \multicolumn{1}{|c|}{ The reaction to the problem } & Score \\
\hline Problem Understanding & No answer at all & 0 \\
\cline { 2 - 3 } & $\begin{array}{l}\text { Writing the known elements without mentioning the elements in } \\
\text { question or vice versa }\end{array}$ & 1 \\
\cline { 2 - 3 } & Writing elements that are known and asked but incompletely & 2 \\
\cline { 2 - 3 } & Writing down the known and asked elements correctly & 3 \\
\hline
\end{tabular}




\begin{tabular}{|l|l|l|}
\hline Compiling a settlement plan & Not planning to solve the problem & 0 \\
\cline { 2 - 3 } & $\begin{array}{l}\text { Planning a solution by making a mathematical picture or model } \\
\text { but it is not quite right }\end{array}$ & 1 \\
\cline { 2 - 3 } & $\begin{array}{l}\text { Planning a solution by creating a mathematical picture or model } \\
\text { correctly }\end{array}$ & 2 \\
\hline Completion of the settlement plan & No solution at all & 0 \\
\cline { 2 - 3 } & Writing down an answer but it's wrong & 1 \\
\cline { 2 - 3 } & $\begin{array}{l}\text { Carrying out the plan by writing down the answers but one answer } \\
\text { or a small number of correct answers }\end{array}$ & 2 \\
\cline { 2 - 3 } & $\begin{array}{l}\text { Carrying out the plan by writing down the answers but half or } \\
\text { most of the answers are correct }\end{array}$ & 3 \\
\cline { 2 - 3 } Interpretation of the results obtained & $\begin{array}{l}\text { Carrying out the plan by writing down the answers completely and } \\
\text { correctly }\end{array}$ & 4 \\
\cline { 2 - 3 } & $\begin{array}{l}\text { Not writing conclusions } \\
\text { Interpreting the results obtained by making inferences but not } \\
\text { being precise }\end{array}$ & 1 \\
\cline { 2 - 3 } & Interpreting the results obtained by drawing conclusions correctly & 2 \\
\hline
\end{tabular}

The final score is calculated by the following equation:

$$
\text { Final Score }=\frac{k}{K} \times 100 \text {, }
$$

where $k$ represents the number of scores obtained, and $K$ represents the maximum number of scores. After scoring the student's answers, the grouping of students who have difficulty solving mathematical problems is done by referring to the opinion of Bandura (2009) that students who get a final score of less than 66 are referred to as students who have difficulty solving mathematical problems.

\section{Results and Discussion}

\subsection{Results}

The research was conducted at one of the public junior high schools in Bandung Regency on 25 students of class VIII-D for the 2020/2021 academic year. Researchers gave tests to students in the form of 4 questions in the form of contextual problems consisting of 2 closed questions and 2 open questions related to the material area and circumference of a circle. Furthermore, the researchers gave a score to the students' answers. Students with a score of less than 66 are categorized as students who have difficulty. The results of student answers with a value of less than 66 were analyzed in depth to find the difficulties experienced by students in solving closed and open problems. The following are the results of the analysis of students' answers to the problems given.

Problem number 1 is a closed problem related to the area of a circle. The physical form of question number 1 is as follows: "Pak Amir has a circle of land. The land will be made a rectangular fish pond with the four corners of the pond on the edge of the land. If the length of the fish pond to be made is 48 meters, and the width is 20 meters, how much land area does Mr. Amir have left?". To this question, most of the students did not answer correctly. Students have difficulty converting problems into mathematical models and have difficulty determining the elements needed in the calculation process. Based on the results of interviews, this is because students have never found the questions given before, and students are not used to solving problems in the form of problem solving. The results of the answers of students who have difficulty in solving question number 1 are presented as follows:

It is known that the length and width of the fish pond to be made are 48 meters and 20 meters, respectively. The question being asked is that how much land is owned by Mr. Amir available?

Answer:

The land area $=A B^{2}+B C^{2}+C A^{2}=48^{2}+20^{2}=2,304+400=\sqrt{2,704}=1,352$

So, the remaining land area belonging to Mr. Amir is 1,352 square meters.

Based on the answer above, sstudents are able to write down the known elements, namely the length of the fish pond of 48 meters and the width of the pond of 20 meters. Students can also write down the questions asked, namely 
the problem of determining the remaining land area. However, students still cannot determine the plan of a mathematical model to solve the problem. Students find the area of land with the following equation: The land area $=A B^{2}+B C^{2}+C A^{2}$. This should not be done. Students should write the formula for the area of a circle to solve it. In addition, students also have not been able to identify what is needed to solve the problem, where students do not determine the length of the unknown radius of the problem. Students are also wrong in doing calculations, where students write $\sqrt{2,704}$ equals 1,352 . This is supported by the results of interviews with the students concerned who say that these students have not really understood the problem given and have difficulty in determining how to find the remaining land area.

Problem number 2 is a closed problem related to the circumference of a circle. In question number 2, students were asked to determine the length of iron needed to make 720 pieces of circular trellis decorative with a radius of $18 \mathrm{~cm}$ and a central angle of $50^{\circ}$. On this question, there were no students who answered correctly because students had difficulty converting the problem into a mathematical model, and many students had difficulty performing the calculation process, namely multiplication and division operations. The results of the answers of students who have difficulty in solving problem number 2 are presented as follows:

It is known that the order of decoration is 720 pieces, the length of the radius of the circle is 18 centimeters, and the measure of the central angle is $50^{\circ}$.

The question asked is that how long is the iron to make the trellis decoration?

Answer:

Length of iron needed $=$ Length of arc $\mathrm{x}$ number of orders

$=\frac{\text { the measure of the central angle }}{360} 2 \times 3.14 \times 18 x \times 720$

$=11,304$ centimeters.

So, the length of iron needed to make 720 trellis decorations is 11,304 centimeters.

Based on the answer above, students are able to identify the elements that are known in the problem, namely the number of decoration orders as many as 720 pieces, the length of the radius of the circle is $18 \mathrm{~cm}$, and the size of the central angle is $50^{\circ}$. Students can also identify the size of the question asked, namely the length of the iron to make a trellis decoration. However, students have not been able to write a plan in the form of a mathematical model to solve the problem. Students multiply the length of the trellis decoration arc by the number of orders to determine the length of iron needed, whereas students should multiply the circumference of the trellis by the number of orders. Thus, students do not arrive at the desired answer. In addition to these answers, there are also students who have been able to write down the elements that are known and asked and can write down the mathematical model made as a plan to solve the problem correctly. Students determine the arc length of the trellis decoration in the form of a circle first. However, the student made a mistake in calculating the multiplication and division operations. In addition, after the length of the trellis decoration arc was obtained, students did not continue their answers according to the plan that had been made previously. This can be seen as follows:

It is known that the number of orders of decoration is 720 pieces, the trellis decoration is in the form of a circle with the radius of the circle is 18 centimeters, and the measure of the central angle is $50^{\circ}$.

The question being asked is what is the minimum length of iron to make a trellis decoration?

Answer:

The minimum length of iron required is the result of multiplying the circumference of the grid by the number of orders. The circumference of a circle is obtained by adding up the length of the arc between the vertices of the circle that forms an angle of $50^{\circ}$ and the two radii of the circle. Suppose that The length of the arc between the bases of a circle that forms an angle of $50^{\circ}$ is $a$, circumference of circle is $k$, the measure of the central angle is $b$. The arc length between the base points of the circle is found by the following process:

$\frac{a}{k}=\frac{b}{360}$

$a=\frac{b}{360} k$

$a=\frac{50}{360} \times 2 \times 3.14 \times 18$

$a=94.2$ centimeters.

Therefore, the minimum length of iron needed is the product of the product between 94.2 and 720 , which is 21,449 centimeters.

Problem number 3 is an open problem related to the circumference of a circle. In question number 3 , students are asked to determine at least 3 possible number of beads needed to decorate the tablecloth with something in the form 
of a circle with a diameter of 2.8 meters and the distance between the beads is in centimeters. To this question, most of the students did not give the correct answer. Based on the results of the interview, this was caused by students who were not used to solving open problems. One of the students' answers to problem number 3 is presented as follows:

It is known that a circular tablecloth with a diameter of 2.8 meters will be beaded with beads with the same distance between the beads.

The problem being asked is that determine 3 possible numbers of beads needed to fill the tablecloth.

Answer:

The number of beads needed with a distance between beads of 3 centimeters is 176 pieces,

The number of beads needed with a distance between beads of 5 centimeters is 88 pieces,

The number of beads needed with a distance between beads of 10 centimeters is 44 pieces,

So, the number of beads needed depends on the distance between the beads.

Based on the answer above, students can write down the elements that are known correctly, namely the diameter of the circle is 2.8 meters, and the installation distance between beads is the same length. Then, students can also write down the questions that are asked correctly, namely 3 possibilities of how many beads are needed. However, students did not include plans in the form of mathematical models used to solve problem number 4. Students immediately wrote answers and gave more than one answer. However, the answers given are not relevant to the given problem, where the student only guesses the answer. This is in accordance with the results of student interviews which said that these students obtained answers based on the results of composing. In addition to these answers, there are also students who can provide one of the answers requested from the questions. However, the student could not provide another answer. The students' answers in question are presented as follows:

It is known that the tablecloth is in the form of a circle with a diameter of 2.8 meters.

The problem being asked is that determine 3 possible numbers of beads needed to fill the tablecloth.

Answer:

The circumference of the tablecloth $=\frac{22}{7} 2.8=0.8$ meters $=880$ centimeters .

Based on this, the number of beads needed is the result of the division between 880 and 2, which is 440 pieces.

Based on the answer above, students write down some of the known elements of the problem, namely he diameter of the circle is 2.8 meters. Then, students do not write down the mathematical model as a plan to solve the problem. However, the student took the right step by finding the circumference of the tablecloth first and doing the calculations correctly. Students give one correct answer to the given problem, which is 440 pieces, even though the question asks students to give 3 possible answers. In this case, students have difficulty in making mathematical models and students have difficulty in giving more than one answer. After being confirmed through interviews, the student can correctly name the mathematical model of the given problem. However, the answer that the student gave regarding the number of beads needed was obtained by guessing. Students do not provide other possible answers because students are confused because the distance of the installation of beads is not known on the questions and students have never solved questions that have more than one answer.

Problem number 4 is an open problem related to the area of a circle. In question number 4 , students are asked to determine the possible total costs that will be spent on planting grass in a circular garden with a diameter of 42 meters. Inside the park, a circular pond will also be formed with an area of no more than 1/4 of the garden area. Land that is not made a pond will be planted with grass with a grass planting fee of IDR 14,000.00. The answers to question number 4 from students are presented as follows:

It is known that a circular garden has a diameter of 42 meters, the area of the pond is the land area, and the cost of planting grass is IDR 14,000.00 per square meters. The question stated, is that what is the total cost spent?

Answer:

The area of the circle $=\pi r^{2}=\frac{22}{7} 21^{2}=1,386$

So, the total cost spent is multiplied between 1,386 and IDR 14,000, which is IDR 19,404,000.00.

Based on the answer above, students write down some of the elements that are known, namely that the diameter of the circle is 42 meters, the area of the pool is $1 / 4$ of the land area, and the cost of planting grass is IDR 14,000.00 per square meters. Students can also write down the question asked, namely the total cost spent. In the answer, students do not write a plan in the form of a mathematical model to solve the problem first so that students do not get the right answer. Students find the area of the park first and do the calculations correctly. However, in determining the possible total cost of planting grass, the student was wrong, where the student multiplied the cost of planting grass, which was IDR $14,000.00$ by the area of the garden, whereas students should have multiplied the cost of planting the grass by the area of the garden planted with grass. This shows that students have difficulty in making plans in the form of 
mathematical models to solve problems. In addition, there are also students who provide one possible total cost of planting grass correctly. The results of the answers from the students in question are presented as follows:

It is known that a circular garden has a diameter of 42 meters, the area of a pond is a quarter of the land area, and the cost of planting a lawn is IDR 14,000.00 per square meter. The question stated, is that what is the total cost spent on grass planting?

Answer:

the total cost spent on grass planting $=$ garden area - pool area

$=\frac{22}{7} 21^{2}-\frac{1}{4} \frac{22}{7} 21^{2}$

$=1,386-1 / 4 * 1,386$

$=1,040$

So, the total cost spent is multiplied between 1,040 and IDR 14,000, which is IDR 14,560,000.00.

Based on the answer above, students only write down some of the known elements of the problem, namely the diameter of the circle is 42 meters, and the area of the circle is $1 / 4$ the land area. Then, students write down the questions that are asked correctly, namely the total cost that will be spent on planting grass. Then, students do not make plans in advance to determine the possible total costs required to plant grass. Students even wrote down an unsystematic way to determine the area of the grass. However, students also determine the exact area of the park. Students also determine the area of the pond and the area of the grass by doing calculations correctly. Then students determine the possible total cost required for planting grass in the park by multiplying the area of grass by the cost of planting grass, which is IDR 14,000.00, and the results obtained are correct. However, in solving the problem in question number 4, students have not been able to give more than 1 answer, considering the command on the question wants students to provide the possibilities of total costs for planting grass in the garden, but students only give 1 possibility. This shows that students have difficulty in providing more than one answer to the given problem. Based on the results of interviews with the students concerned, this is because students never solve questions that have more than one answer. Apart from that, there are students who have been able to convert the problem into a mathematical model as an appropriate plan, but students have difficulty implementing the plan. Students make mistakes in multiplication and division operations so that students do not get the desired answer. In addition, students also do not provide another possibility for the cost of planting grass. In other words, students have difficulty in giving more than one answer. Based on the results of interviews with these students, this is because students never solve questions that have more than one answer.

\subsection{Discussion}

Based on the data that has been presented, in closed problem number 1 which is a contextual problem related to the concept of the area of a circle, students have difficulty in writing down the known elements of the problem. This was obtained from the answers of students who only wrote down some of the known elements. In question number 1 , many students also have difficulty in making plans for mathematical models to solve the problem. This is in line with the results of research conducted by Fitriani et al. (2018) that the difficulties experienced by students in solving geometry problems are difficulties in translating problems into mathematical models. Students also have difficulty in determining the elements needed to solve problems that are not known about the problem, namely the length of the radius of the garden. In addition, in solving problem number 1, students also have difficulty in the calculation process, where students make mistakes in multiplication operations. This is in accordance with what was expressed by Rusyda, Kusnandi and Suhendra (2017) that students' difficulties can be seen from operating errors. This is because students are not careful in doing calculations and in a hurry to solve the problems given so that students do not get the right answer.

Problem number 2 is a closed problem related to the circumference of a circle. Most of the students were able to identify the known and asked elements of the problem correctly. However, many students have difficulty in making plans in the form of mathematical models to solve problems. This can be seen in the answers of students who make mathematical models that are not in accordance with the given problem. In addition, students also experience difficulties in carrying out the plans that have been made, where students do not complete the answers according to the plan, and students have difficulty in performing multiplication and division operations such as the student answers in the answers to question number 2 which first.

In question number 3 which is an open problem related to the circumference of a circle, students have difficulty understanding the information contained in the problem, where students only write down some of the known elements of the problem. Students also have difficulty in making mathematical models which are planing to solve problems. This can be seen in the student's answers in the answer to question number 3 from the first student who immediately gave answers without making a plan beforehand. Meanwhile, some students who were able to make mathematical models based on this problem were fooled by the problems given because there was no information about the distance between the rosary on the tablecloth, so students had difficulty implementing the plan to determine the number of 
beads needed. In addition, students have difficulty in providing other possibilities of the number of rosary needed, where students only give one answer like the student's answer in the answer to question number 3 from the second student.

In question number 4 which is an open problem related to the area of the circle, students are able to understand the information from the questions given even though students do not write down the elements that are known correctly. This can be seen in the student's answers in the answer to question number 7 from the second student, where students have been able to solve the problem in the right way, even though the student did not write a plan to solve the problem first. In addition, there are also students who make plans in the form of mathematical models after obtaining all the information needed to solve the problems on this matter. However, there are also students who have difficulty in making mathematical models as a plan to solve problems such as the student answers in the answer to question number 4 from the first student. Another difficulty experienced by students in solving problems in problem number 4 is in the calculation process. Many students still make mistakes in performing multiplication and division operations which cause students not to get the right answer. This is caused by students who are less careful in performing arithmetic operations.

Based on the data that has been presented, both in solving closed and open problems, many students have difficulty converting the problem into a mathematical model as a plan to solve the given problem. This is in line with the results of research conducted by Wicaksono and Martyanti (2019) which states that students have difficulty in determining completion procedures. Data from interviews conducted by researchers with one of the students supports this, where students say that the stage to solve the most difficult problem is determining the method used to solve the problem, so students cannot solve the problem given correctly. This is because students feel that they have never encountered problems in the questions given previously and students are not used to solving a problem-based questions. Students also do not really understand the information contained in the questions, where students still have difficulty in identifying the known elements of the questions correctly, so students find it difficult to make plans for solving them. In line with this, the results of research conducted by Jupri et al. (2014) suggest that students' lack of understanding of the problems given makes it difficult for students to determine the right method to solve problems. Students also experience difficulties in carrying out plans and calculations, where there are still many students who make mistakes in multiplication and division operations. This is in line with the results of research conducted by Wicaksono and Martyanti (2019) which states that the difficulty of students in solving problems in the circle material is difficulty in counting.

In addition, in solving open-ended problems, students also have difficulty in giving more than one answer because students are not accustomed to solving open-ended questions that have more than one answer. This is in accordance with the results of research conducted by Jupri et al. (2014) which states that students have difficulty in determining other methods that can be used to solve problems. The data from the researcher's interview with one of the students supports this. Students said that students never found a question that had more than one answer. This is also supported by a document in the form of a student exercise book, where the practice questions given to students are closed problems only.

By referring to the problem solving indicators that have been determined previously, the most difficulties experienced by students in fulfilling the indicators of solving closed and open problems are difficulties in formulating problems or making mathematical models. The difficulty in indicators of implementing strategies to solve other problems is that there are still students who have difficulty implementing the plans that have been made. There are also students who were not able to use the information that is known from the questions, there are even students who make errors in calculations. In solving open-ended problems, students have not been able to give more than one answer because students are not accustomed to solving math problems that have more than one answer. In the indicators of identification of elements that are known and asked, there are still students who were not able to write down the elements that are known and asked correctly, so that students cannot make a problem-solving plan. In the indicator of result presentation, many students have been able to do well. However, because the results obtained are incorrect, the conclusions made are inaccurate.

The difficulties experienced in solving closed and open problems are caused because students feel that the problem given is something new. Students are also less careful in understanding the problems given. Then, students have not mastered the material on the topic of circles. Furthermore, students are less careful in performing arithmetic operations, both in multiplication and division. Finally, students are not accustomed to solving problems in the form of open problem solving or questions that have more than one answer

\section{Conclussion}

Based on the data that has been presented, in solving closed and open problems, students have difficulty. Students have difficulty in converting the problem into the form of a mathematical model as a plan to solve the problem. Students also still have difficulty in determining the required elements. In this study, students even had difficulty in performing multiplication and division operations. Meanwhile, in solving open-ended problems, students also had difficulty in giving more than one answer. The difficulties experienced by students are caused because students feel the problem given is something new. Students are also 
less careful in understanding the problems given. In fact, there are students who still do not master the material and are less thorough in performing arithmetic operations.

\section{References}

Fitriani, N., Suryadi, D., and Darhim. (2018). Analysis of Mathematical Abstraction on Concept of Three Dimensional Figure with Curved Surfaces of Junior High School Students. Journal of Physics: Conference Series, 1132(1), 1-7.

Stacey, K. (2011). The PISA View of Mathematical Literacy in Indonesia. Journal on Mathematics Education, 2(2), 95-126.

Ministry of Education and Culture of Republic Indonesia. (2014). Permendikbud Number 58 of 2014. Jakarta: Ministry of Education and Culture of Republic Indonesia.

Miles, M. B. and Huberman, A. M. (1994). Qualitative Data Analysis, Second Edition. United States of America: Sage Publication.

Bandura, A. (2009). Self-efficacy in Changing Societies. Cambridge, UK: Cambridge University Press.

Wicaksono, A. B., and Martyanti, A. (2019). Analysis of Junior High School Students' Errors in Solving Mathematical Problems for The Topic of Circle. Indonesian Journal of Mathematics Education, 2(2), 61-68.

Jupri, A., Drijvers, P., and Heuvel-Panhuizen, M. V. D. (2014). Student Difficulties in Solving Equations from an Operational and a Structural Perspective. International Electronic Journal of Mathematics Education, 9(1), 39-55.

Buchanan, N. K. (1987). Factors Contributing to Mathematical Problem-Solving Performance: An Explanatory Study. Educational Studies in Mathematics, 18(4), 399-415.

Mourtos, N. J., Okamoto, N. D., and Rhee, J. (2004). Open-Ended Problem-Solving Skills in Thermal Fluids Engineering. Global Journal of Engineering Education, 8(2), 189-200.

Rusyda, N. A., Kusnandi, K., and Suhendra, S. (2017). A Cognitive Analysis of Students' Mathematical Problem-Solving Ability on Geometry. Journal of Physics: Conference Series, 895(1), 1-7.

Abidin, M., Retnawati, H. (2019). A Diagnosis of Difficulties in Answering Questions of Circle Material on Junior High School Students. Jurnal Penelitian dan Evaluasi Pendidikan, 23(2), 144-155.

Retnawati and Heri. (2017). Diagnosing the Junior High School Students' Difficulties in Learning Mathematics. International Journal on New Trends in Education and Their Implications, 8(1), 33-50. 